\title{
Breast cancer screening attendance in two Swiss regions dominated by opportunistic or organized screening
}

\author{
Monika Eichholzer ${ }^{1 *}$ (D) Aline Richard ${ }^{1}$, Sabine Rohrmann', Seraina M. Schmid ${ }^{2,3}$, Cornelia Leo ${ }^{4}$, \\ Dorothy J. Huang ${ }^{5}$ and Uwe Güth ${ }^{6}$
}

\begin{abstract}
Background: In Switzerland, the French-speaking region has an organized breast cancer (BC) screening program; in the German-speaking region, only opportunistic screening until recently had been offered. We evaluated factors associated with attendance to breast cancer screening in these two regions.

Methods: We analyzed the data of 50-69 year-old women $(n=2769)$ from the Swiss Health Survey 2012. Factors of interest included education level, place of residence, nationality, marital status, smoking history, alcohol consumption, physical activity, diet, self-perceived health, history of chronic diseases and mental distress, visits to medical doctors and cervical and colorectal cancer screening. Outcome measures were dichotomized into $\leq 2$ years since most recent mammography versus $>2$ years or never.

Results: In the German- and French-speaking regions, mammography attendance within the last two years was $34.9 \%$ and $77.8 \%$, respectively. In the French region, moderate alcohol consumption (adjusted OR 2.01, $95 \% \mathrm{Cl}$ 1.28-3.15) increased screening attendance. Compared to those with no visit to a physician during the recent year, women in both regions with such visits attended statistically significantly more often BC screening (1-5 times vs. no visit: German (adjusted OR 3.96, $95 \% \mathrm{Cl} 2.58-6.09$ ); French: OR 7.25, $95 \% \mathrm{Cl}$ 4.04-13.01). Non-attendance to cervical screening had a negative effect in both the German (adjusted OR 0.44, $95 \% \mathrm{Cl} 0.25-0.79$ ) and the French region (adjusted OR 0.57, $95 \% \mathrm{Cl} 0.35-0.91$ ). The same was true for colorectal cancer screening (German (adjusted OR 0.66, 95 \% Cl 0.52-0.84); French: OR 0.52, $95 \% \mathrm{Cl}$ 0.33-0.83). No other factor was associated with BC screening and none of the tests of interaction comparing the two regions revealed statistically significant results.

Conclusion: The effect of socio-demographic characteristics, lifestyle, health factors and screening behavior other than mammography on non-attendance to BC screening did not differ between the two regions with mainly opportunistic and organized screening, respectively, and did not explain the large differences in attendance between regions. Other potential explanations such as public promotion of attendance for BC screening, physicians' recommendations regarding mammography participation or women's beliefs should be further investigated.
\end{abstract}

Keywords: Breast cancer, Mammography screening, Attendance, Opportunistic screening, Organized screening program

\footnotetext{
* Correspondence: monika.eichholzer@ifspm.uzh.ch

${ }^{1}$ Division of Chronic Disease Epidemiology, Epidemiology, Biostatistics and

Prevention Institute, University of Zurich, Hirschengraben 84, CH-8001 Zurich,

Switzerland

Full list of author information is available at the end of the article
} 


\section{Background}

Opportunistic mammography is a screening tool used by women on their own initiative or following the advice of their gynecologist or general practitioner. Organized breast cancer (BC) screening is a free service offered periodically to asymptomatic women aged e.g. 50-69 years depending on the recommendations of various countries. These screening programs are performed according to guidelines for quality assurance [1, 2]. In Switzerland, organized BC screening programs coexist with opportunistic mammography screening. The Federal Office of Social Insurance decided in 1999 to reimburse biennial mammography screening for women aged 50 years and above through the Swiss compulsory health insurance system, when performed within a qualityassured program [3]. In 2012, the whole French-speaking region of Switzerland was covered by an organized BC screening program. The German-speaking region of Switzerland, on the other hand, started introducing organized screening programs in 2010 in the canton of Thurgovia, 2011 in the cantons of St. Gallen and Grisons, 2013 in the canton of Berne, and 2014 in the canton of Basel-City but not in the rest of the German speaking cantons. Thus, when the 2012 Swiss Health Survey (SHS) was carried out, mainly opportunistic BC screening existed in the German-speaking part of Switzerland [4].

In previous studies, non-attendance to BC screening was associated with lifestyle factors such as smoking [5], lower physical activity [6], and alcohol abstinence [7]. In addition, health-related factors such as poor selfperceived health [7], serious psychological distress [8], and non-attendance to cervical cancer screening were associated with non-attendance [9]. Socio-demographic factors such as lower level of education and lower occupational class [10], living without partner [11, 12], and nationality/migration status [13] may be of importance. The few studies that considered this topic found evidence that factors associated with non-attendance to mammography screening might differ between opportunistic and organized BC screening programs [14, 15].

In a previous analysis of Swiss data on the association between body mass index (BMI) and BC screening attendance, we observed a higher attendance of overweight women overall and of women from the German-speaking region, but not of women from the French-speaking region [16]. Data on factors associated with non-attendance to $\mathrm{BC}$ screening according to the type of screening practices are not available in Switzerland and are scarce in other countries.

The aim of the present study was to evaluate further factors that were associated with non-attendance to $\mathrm{BC}$ screening according to the main types of screening practices (opportunistic or organized) in two regions of
Switzerland. The study sample allowed evaluating various socio-demographic, life-style and health factors in relation to women who do not adhere to mammography screening. In many studies, data on non-attenders are not available. Data from Switzerland is of particular interest, since both types of screening are available simultaneously in a single country, and not-as is usually the case-one screening type being replaced by another.

All analyses were based on data of the Swiss Health Survey (SHS) 2012, and were restricted to 50-69 yearold women, the main target group for BC screening in Switzerland [3].

\section{Methods}

\section{Study population and design}

For the present analysis data of the cross-sectional 2012 SHS conducted by the Swiss Federal Statistical Office [17] (Legal basis: Swiss Statistics, Ordinance of the Conduct of Federal statistical Surveys of 30 June 1993) were used. This survey was comprised of participants randomly selected to represent the Swiss permanent population, i.e. Swiss citizens and foreigners with a legal work permit of both sexes aged 15 years and older. Participants were selected from the resident population living in a private household based on registries of inhabitants. Individuals living in collective households such as nursing homes, military bases, prisons, monasteries, boarding schools, hospitals, hotels etc. were not included. Of a sample of 41,008 individuals, a total of 21,597 agreed to participate in the survey (participation rate $54 \%$ ). The level of representativeness of the sample was corrected with appropriate weighting factors from the telephone interview. All individuals were interviewed by telephone (see below "statistical analyses"). Furthermore, all participants were invited to complete a written questionnaire. Only German-, French- or Italian-speaking individuals were included in the survey.

A total of 11,314 women participated in the SHS 2012. Of these, 3,614 women (31.9\%) were 50-69 years old. After excluding women with missing information on BC screening $(n=469)$ and women living in the Italian region of Switzerland $(n=247)$, our sample consisted of 2,898 women. In addition, we excluded women with missing information on demographics $(n=18)$, on lifestyle variables $(n=39)$, on chronic diseases or other screening tests $(n=72)$. Our final dataset consisted of 2,769 participants.

\section{Measurements}

Outcome measure: BC screening status was calculated based on self-reported information on the last $\mathrm{BC}$ screening date and then dichotomized in $\leq 2$ years since most recent mammography versus $>2$ years or never. 
Explorative variables: For socio-demographic variables we included educational level (low: compulsory education or less, middle: secondary education vs. high: tertiary education), nationality (Non-Swiss vs. Swiss), area of residence (rural vs. urban), and marital status (single, widowed, divorced, separated, dissolved partner vs. married, registered partnership). Lifestyle factors comprised smoking status (current smoker, former smoker vs. women who have never smoked), hazardous chronic alcohol consumption ( $\geq 20$ g ethanol daily, $<20$ g vs. less than once a month or none) [18], physical activity ( $\geq 150 \mathrm{~min}$ per week vs. less) [19], attention to diet (yes vs. no), and as a potential confounder, body mass index (BMI) categorized into underweight (BMI $<18.5 \mathrm{~kg} / \mathrm{m}^{2}$ ), normal weight (BMI $18.5-24.9 \mathrm{~kg} / \mathrm{m}^{2}$ ), overweight (BMI $25.0-29.9 \mathrm{~kg} / \mathrm{m}^{2}$ ), and obesity (BMI $\geq 30 \mathrm{~kg} / \mathrm{m}^{2}$ ). Health-related factors included chronic diseases (self-reported ongoing diseases or health problems lasting for at least 6 months or expected to last a further 6 months), self-perceived health status (fair, poor, very poor vs. very good, good), visits to a physician within the recent year (no, $1-5,6-10,>10$ times), psychological distress measured by the 5-Item Mental Health Index (MHI-5) (high, moderate, vs. low), cervical cancer screening with the Papanicolaou test $(\leq 3$ years since most recent screening vs. $>3$ years or never), and colorectal cancer screening with colonoscopy (yes [ever] vs. no [never]).

In addition, the question "Who prompted you to attend to this mammography ("own initiative", "following the recommendation of a medical doctor", "in the context of a screening program")" was evaluated.

In the Swiss Health Survey, the entire study sample comprised the German-, French- and Italian-speaking parts of Switzerland, the language regions being defined by the language of the municipality of the study participant's residence. In the present study, we included the German- and the French-speaking regions and compared them with each other.

\section{Statistical analyses}

We evaluated potential differences of attendance to $\mathrm{BC}$ screening in the German-speaking region with mainly opportunistic screening and in the French-speaking region of Switzerland with population based programs depending on socio-demographics, lifestyle and healthrelated factors as well as non-attendance to screening other than mammography.

In our analyses, we used two logistic regression models. Model 1 was unadjusted and model 2 was adjusted for all other demographic, lifestyle and health factors as shown in Table 1, with the exception of cervical and colorectal cancer screening.

Tests for interaction were done using the crossproduct terms of each of the exposure variables (demographics, lifestyle and health factors) with the dichotomized region of Switzerland (German vs. French); this interaction term was evaluated using the Wald test. $P$-values $<0.05$ were considered statistically significant.

Sampling weights of the telephone interviews were provided by the Swiss Federal Statistical Office (SFSO) and applied to the data of the present analyses to calculate descriptive characteristics (percentages) and to conduct logistic regression analyses. The sampling weights include a comparison with the permanent 2012 Swiss population with regard to sex, age, geographic region and nationality (Swiss vs. others). All calculations and analyses were performed with STATA/SE, version 13 (StataCorp, College Station, Texas).

\section{Results}

Table 1 summarizes socio-demographic characteristics, lifestyle and health factors, and screening behavior other than mammography of the 1938 eligible women of the German-speaking region and of the 831 women of the French-speaking region of Switzerland participating in the 2012 SHS. Of the German-speaking women, higher percentages reached the recommendations for physical activity (76.2 vs. $60.3 \%$ ), paid attention to their diet (86.6 vs. $64.8 \%$ ), declared themselves to be in good health (81.1 vs. $71.4 \%)$ and had a cervical cancer screening test (90.8 vs. $78.3 \%$ ) compared to French-speaking women.

Table 2 shows that in the German-speaking region of Switzerland with its mainly opportunistic BC screening, $28.8 \%$ of the 50-69 year-old women never had a BC screening examination, $34.9 \%$ had one within the past two years, and $36.3 \%$ had a mammography more than two years ago. The corresponding values in the Frenchspeaking region, with population based $\mathrm{BC}$ screening programs, were $7.3 \%, 77.8 \%$, and $15.0 \%$. Of the women who attended $\mathrm{BC}$ screening in the German-speaking region, $16.8 \%$ did it on their own initiative, $73.1 \%$ followed the recommendation of a medical doctor, and $10.1 \%$ in the context of a screening program. In the French-speaking region, the corresponding values were $8.5 \%, 36.5 \%$ and $55.1 \%$, respectively.

Associations between socio-demographic characteristics, lifestyle and health-related factors, screening behavior other than mammography, and BC screening attendance are presented separately for the two regions in Table 3. In the German-speaking region, BC screening attendance was significantly less common among women not adhering to cervical cancer screening (adjusted OR 0.44, $95 \%$ CI 0.25-0.79) and colonoscopy (adjusted OR $0.66,95 \%$ CI $0.52-0.84)$. In the French-speaking region, moderate alcohol consumption (adjusted OR 2.01, $95 \%$ CI 1.28-3.15) was associated with significantly increased attendance to $\mathrm{BC}$ screening. As in the German-speaking 
Table 1 Baseline characteristics (socio-demographic, lifestyle/health factors, and screening behavior other than mammography) in 50-69 year-old women: Swiss Health Survey $2012^{a}$

\begin{tabular}{|c|c|c|c|}
\hline & & German region & French region \\
\hline Women, $\mathrm{n}$ & & 1938 & 831 \\
\hline \multirow[t]{2}{*}{ Age, mean } & & 58.5 & 59.1 \\
\hline & & $\%$ & $\%$ \\
\hline \multirow[t]{3}{*}{ Educational level } & High & 19.4 & 24.9 \\
\hline & Middle & 66.5 & 56.1 \\
\hline & Low & 14.1 & 19.0 \\
\hline \multirow[t]{2}{*}{ Nationality } & Swiss & 89.9 & 84.7 \\
\hline & Non-Swiss & 10.1 & 15.3 \\
\hline \multirow[t]{2}{*}{ Place of residence } & Urban & 71.1 & 74.5 \\
\hline & Rural & 28.9 & 25.5 \\
\hline \multirow[t]{2}{*}{ Marital status } & married/registered partnership & 66.0 & 59.4 \\
\hline & Single, divorced/dissolved partnership, separated, widowed & 34.0 & 40.6 \\
\hline \multirow[t]{4}{*}{ BMI } & Underweight $\left(\mathrm{BMl}<18.5 \mathrm{~kg} / \mathrm{m}^{2}\right)$ & 3.6 & 4.0 \\
\hline & Normal weight (BMI $18.5-24.9 \mathrm{~kg} / \mathrm{m}^{2}$ ) & 55.8 & 58.1 \\
\hline & Overweight (BMI 25-29.9kg/m²) & 27.5 & 27.8 \\
\hline & Obesity (BMI $\geq 30 \mathrm{~kg} / \mathrm{m}^{2}$ ) & 13.1 & 10.2 \\
\hline \multirow[t]{3}{*}{ Smoking status } & Never smoker & 50.9 & 44.1 \\
\hline & Ex-smoker & 25.7 & 30.5 \\
\hline & Current smoker & 23.4 & 25.4 \\
\hline \multirow[t]{3}{*}{ Alcohol } & Never & 27.6 & 33.6 \\
\hline & $<20 \mathrm{~g}$ ethanol per day & 68.5 & 60.0 \\
\hline & $\geq 20$ g ethanol per day & 4.0 & 6.4 \\
\hline \multirow[t]{2}{*}{ Physical activity } & $\geq 150$ min. per week & 76.2 & 60.3 \\
\hline & $<150$ min. per week & 23.7 & 39.7 \\
\hline \multirow[t]{2}{*}{ Attention to diet } & Yes & 86.6 & 64.8 \\
\hline & No & 13.4 & 35.2 \\
\hline \multirow[t]{2}{*}{ Self-perceived health } & Good, very good & 81.1 & 71.4 \\
\hline & Fair, poor, very poor & 18.9 & 28.6 \\
\hline \multirow[t]{2}{*}{ Chronic disease ${ }^{b}$} & No & 57.0 & 59.5 \\
\hline & Yes & 43.0 & 40.5 \\
\hline \multirow[t]{3}{*}{ Psychological distress } & Low & 82.8 & 73.3 \\
\hline & Moderate & 12.0 & 18.3 \\
\hline & High & 4.9 & 8.4 \\
\hline \multirow[t]{4}{*}{ Visits to a physician within the recent year } & no & 16.5 & 10.7 \\
\hline & 1 to 5 times & 62.8 & 66.4 \\
\hline & 6 to 10 times & 12.6 & 13.9 \\
\hline & $>10$ times & 7.8 & 9.1 \\
\hline \multirow[t]{2}{*}{ Cervical cancer screening } & Yes & 90.8 & 78.3 \\
\hline & No & 9.2 & 21.7 \\
\hline \multirow[t]{2}{*}{ Colorectal cancer screening } & Yes & 36.0 & 35.9 \\
\hline & No & 64.0 & 64.1 \\
\hline
\end{tabular}

${ }^{a}$ all proportions are weighted according the Swiss general population, except $n$

${ }^{\mathrm{b}}$ self-reported ongoing diseases or health problems lasting for at least 6 months or expected to last further 6 months 
Table 2 Attendance to mammography in the German- and French-speaking regions of Switzerland in 50-69 years-old women: Swiss Health Survey $2012^{a}$

\begin{tabular}{|c|c|c|c|}
\hline & & German region & French region \\
\hline \multirow{2}{*}{\multicolumn{2}{|c|}{ Women, n }} & 1938 & 831 \\
\hline & & $\%$ & $\%$ \\
\hline \multirow[t]{3}{*}{ Mammography } & Never & 28.8 & 7.3 \\
\hline & Within the last 2 years & 34.9 & 77.8 \\
\hline & More than 2 years ago & 36.3 & 15.0 \\
\hline \multicolumn{4}{|c|}{ Who prompted you to attend to this mammography? } \\
\hline & Own initiative & 16.8 & 8.5 \\
\hline & Following the recommendation of a medical doctor & 73.1 & 36.5 \\
\hline & In the context of a screening program & 10.1 & 55.1 \\
\hline
\end{tabular}

all proportions are weighted according to the Swiss general population, except $n$

region, low attendance to cervical screening and colonoscopy was statistically significantly associated with a lower attendance to BC screening (adjusted OR 0.57, $95 \%$ CI $0.35-0.91$ and OR 0.52, $95 \%$ CI 0.33-0.83). Compared to those with no visit to a physician during the recent year, women in both regions with such visits attended statistically significantly more often $\mathrm{BC}$ screening (1-5 times vs. no visit: German (OR 3.96, 95 \% CI 2.58-6.09); French: OR 7.25, $95 \%$ CI 4.04-13.01). With the exception of the thus far mentioned associations with $\mathrm{BC}$ screening, none of the other socio-demographic and lifestyle factors (education, living in urban/rural areas, nationality, marital status, smoking status, attention to diet and physical activity, and health issues, characterized by self-perceived health, chronic disease status and mental distress) was statistically significantly associated with mammography use, in both the German and the French-speaking regions. Furthermore, none of the tests of interaction comparing each single explorative variable with the two regions revealed a statistically significant result.

\section{Discussion}

The participation rate of $77.8 \%$ in the French-speaking region of Switzerland lies within the range of other European countries' screening uptake of 55 to $90 \%$ [20]. The much lower mammography attendance in the German-speaking region of Switzerland (34.9\%) confirms previous observations that women are more likely to adhere to $\mathrm{BC}$ screening in countries with screening programs than in those with opportunistic screening $[15,21]$. Factors associated with non-attendance to BC screening might differ between opportunistic and organized BC screening programs $[12,14,15]$ and the question arises whether organized screening programs "rescue" distinct subgroups of women who fall through the opportunistic screening net? In the present study, we did not find any socio-demographic, lifestyle or health factors, which could explain the large difference in $\mathrm{BC}$ screening attendance between the French- and the German-speaking regions of Switzerland. None of the interaction terms were statistically significant.

In contrast to previous observations demonstrating that a socio-economic gradient is evident in BC screening attendance in opportunistic but not in populationbased programs [14], in the present study, neither attendance to opportunistic nor organized $\mathrm{BC}$ screening were associated with educational level, nationality, living in urban or rural areas or marital status. Previous studies observed that women with higher educational levels reported greater screening participation [11, 22], although not consistently so [23-25]. It should be noted that in Switzerland, all residents are obliged by law to have a health insurance, thus, BC screening costs are basically covered [26]. This might explain why education, as potential indicator of the women's socioeconomic status, was not associated with $\mathrm{BC}$ screening attendance in the present study. In many studies $[11,27,28]$, marital status was associated with higher attendance to $\mathrm{BC}$ screening. Partners seem to encourage each other towards health conscious behaviors [29]. A survey carried out in Geneva, Switzerland, found that men had more favorable attitudes towards BC screening than women [30]. Living with a partner, but not being married or registered (registration is in Switzerland only an option for couples of the same sex), is considered in the Swiss Health Survey as being single. This may explain why we did not observe an association between marital status and $\mathrm{BC}$ screening attendance.

In our study, additional socio-demographic factors such as nationality and living in a rural or urban area also had no effect on screening attendance rates in both regions. Lower screening participation in urban areas has previously been reported from various European countries [25, 31, 32]. The different demographic composition of urban and rural areas in relation to migrants, education and economic level of the inhabitants may 
Table 3 Associations of mammography attendance ${ }^{a}$ with socio-demographic, lifestyle/health factors, and screening behavior other than mammography in 50-69 years-old women: Swiss Health Survey $2012^{\mathrm{b}}$

\begin{tabular}{|c|c|c|c|c|c|c|c|c|c|c|}
\hline & & \multicolumn{4}{|c|}{ German region } & \multicolumn{4}{|c|}{ French region } & \multirow[b]{3}{*}{ P-Interaction } \\
\hline & & \multicolumn{2}{|c|}{ unadjusted } & \multicolumn{2}{|c|}{ multivariable adjusted $^{c}$} & \multicolumn{2}{|c|}{ unadjusted } & \multicolumn{2}{|c|}{ multivariable adjusted $^{c}$} & \\
\hline & & $O R$ & $95 \% \mathrm{Cl}$ & $O R$ & $95 \% \mathrm{Cl}$ & $O R$ & $95 \% \mathrm{Cl}$ & $O R$ & $95 \% \mathrm{Cl}$ & \\
\hline \multirow[t]{3}{*}{ Educational level } & High & 1 & & 1 & & 1 & & 1 & & \\
\hline & Middle & 1.27 & $(0.94-1.72)$ & 1.17 & $(0.85-1.60)$ & 1.02 & $(0.63-1.63)$ & 0.85 & $(0.50-1.44)$ & \\
\hline & Low & 1.16 & $(0.75-1.80)$ & 1.08 & $(0.68-1.71)$ & 0.86 & $(0.48-1.54)$ & 0.60 & $(0.32-1.12)$ & 0.208 \\
\hline \multirow[t]{2}{*}{ Nationality } & Swiss & 1 & & 1 & & 1 & & 1 & & \\
\hline & Non-Swiss & 0.95 & $(0.59-1.51)$ & 0.91 & $(0.57-1.46)$ & 1.32 & $(0.70-2.49)$ & 1.41 & $(0.73-2.73)$ & 0.360 \\
\hline \multirow[t]{2}{*}{ Place of residence } & Urban & 1 & & 1 & & 1 & & 1 & & \\
\hline & Rural & 1.14 & $(0.88-1.47)$ & 1.16 & $(0.88-1.51)$ & 0.86 & $(0.57-1.29)$ & 0.96 & $(0.60-1.52)$ & 0.255 \\
\hline \multirow[t]{2}{*}{ Marital status } & married / registered partnership & 1 & & 1 & & 1 & & 1 & & \\
\hline & $\begin{array}{l}\text { Single, divorced / dissolved partnership, } \\
\text { separated, widowed }\end{array}$ & 0.78 & $(0.61-1.01)$ & 0.82 & $(0.63-1.06)$ & 0.77 & $(0.53-1.13)$ & 0.76 & $(0.51-1.14)$ & 0.808 \\
\hline \multirow[t]{3}{*}{ Smoking status } & Never smokers & 1 & & 1 & & 1 & & 1 & & \\
\hline & Ex-smoker & 1.33 & $(1.01-1.74)$ & 1.28 & $(0.96-1.70)$ & 1.17 & $(0.74-1.86)$ & 0.97 & $(0.59-1.59)$ & \\
\hline & Current smokers & 0.87 & $(0.64-1.17)$ & 0.92 & $(0.67-1.26)$ & 0.76 & $(0.49-1.18)$ & 0.73 & $(0.45-1.18)$ & 0.399 \\
\hline \multirow[t]{3}{*}{ Alcohol } & Never & 1 & & 1 & & 1 & & 1 & & \\
\hline & $<20 \mathrm{~g}$ ethanol per day & 1.19 & $(0.92-1.55)$ & 1.21 & $(0.92-1.59)$ & 1.86 & $(1.24-2.77)$ & 2.01 & $(1.28-3.15)$ & \\
\hline & $\geq 20 \mathrm{~g}$ ethanol per day & 0.86 & $(0.49-1.52)$ & 0.94 & $(0.53-1.67)$ & 1.00 & $(0.50-2.01)$ & 0.98 & $(0.45-2.11)$ & 0.270 \\
\hline \multirow[t]{2}{*}{ Physical activity } & $\geq 150$ min. per week & 1 & & 1 & & 1 & & 1 & & \\
\hline & $<150$ min. per week & 0.88 & $(0.67-1.15)$ & 0.91 & $(0.68-1.21)$ & 0.79 & $(0.54-1.14)$ & 0.73 & $(0.49-1.09)$ & 0.355 \\
\hline \multirow[t]{2}{*}{ Attention to diet } & Yes & 1 & & 1 & & 1 & & 1 & & \\
\hline & No & 0.86 & $(0.60-1.22)$ & 1.01 & $(0.70-1.44)$ & 0.81 & $(0.55-1.19)$ & 1.04 & $(0.69-1.56)$ & 0.565 \\
\hline \multirow[t]{2}{*}{ Self-perceived health } & Good, very good & 1 & & 1 & & 1 & & 1 & & \\
\hline & Fair, poor, very poor & 1.25 & $(0.92-1.70)$ & 1.08 & $(0.75-1.55)$ & 1.81 & $(1.17-2.80)$ & 1.66 & $(0.98-2.81)$ & 0.205 \\
\hline \multirow[t]{2}{*}{ Chronic disease $^{d}$} & No & 1 & & 1 & & 1 & & 1 & & \\
\hline & Yes & 1.24 & $(0.99-1.57)$ & 0.90 & $(0.69-1.17)$ & 1.60 & $(1.09-2.36)$ & 1.13 & $(0.72-1.77)$ & 0.390 \\
\hline \multirow[t]{3}{*}{ Psychological distress } & Low & 1 & & 1 & & 1 & & 1 & & \\
\hline & Moderate & 1.11 & $(0.78-1.59)$ & 1.03 & $(0.72-1.47)$ & 1.32 & $(0.83-2.10)$ & 1.16 & $(0.69-1.94)$ & \\
\hline & High & 0.85 & $(0.47-1.53)$ & 0.70 & $(0.38-1.30)$ & 1.36 & $(0.69-2.69)$ & 1.33 & $(0.61-2.86)$ & 0.219 \\
\hline \multirow[t]{3}{*}{ Visits to a physician within the recent year } & no & 1 & & 1 & & 1 & & 1 & & \\
\hline & $1-5$ times & 4.02 & $(2.64-6.11)$ & 3.96 & $(2.58-6.09)$ & 7.54 & $(4.31-13.17)$ & 7.25 & $(4.04-13.01)$ & \\
\hline & 6 to 10 times & 4.31 & $(2.57-7.21)$ & 4.26 & (2.49-7.30) & 6.71 & (3.35-13.46) & 5.51 & $(2.60-11.68)$ & \\
\hline
\end{tabular}


Table 3 Associations of mammography attendance ${ }^{a}$ with socio-demographic, lifestyle/health factors, and screening behavior other than mammography in 50-69 years-old women: Swiss Health Survey $2012^{\mathrm{b}}$ (Continued)

\begin{tabular}{|c|c|c|c|c|c|c|c|c|c|c|}
\hline & $>10$ times & 6.43 & $(3.72-11.13)$ & 7.03 & $(3.88-12.73)$ & 6.14 & $(2.69-13.98)$ & 6.07 & $(2.54-14.52)$ & 0.976 \\
\hline \multirow[t]{2}{*}{ Cervical cancer screening } & Yes & 1 & & 1 & & 1 & & 1 & & \\
\hline & No & 0.38 & $(0.21-0.69)$ & 0.44 & $(0.25-0.79)$ & 0.44 & $(0.29-0.67)$ & 0.57 & $(0.35-0.91)$ & 0.786 \\
\hline \multirow[t]{2}{*}{ Colorectal cancer screening } & Yes & 1 & & 1 & & 1 & & 1 & & \\
\hline & No & 0.56 & $(0.44-0.71)$ & 0.66 & $(0.52-0.84)$ & 0.43 & $(0.28-0.65)$ & 0.52 & $(0.33-0.83)$ & 0.235 \\
\hline
\end{tabular}

amammography screening adherence defined by participation within the last 2 years

b weighted according the Swiss general population
cadjusted for all factors shown in Table 1, except cervical cancer and colonoscopy screening

$\mathrm{d}_{\mathrm{s}}$ elf-red for all factors shown in Table 1, except cervical cancer and colonoscopy screening 
contribute to such differences [32]. Participation to the Swiss Health Survey was limited to German-, French- or Italian-speaking individuals. Thus, the group of immigrants in the present study is restricted to those who speak German, French or Italian. It does therefore not reflect reality in Switzerland in relation to the various immigrant groups living in this country, and may have excluded minorities prone to non-attendance of $\mathrm{BC}$ screening [11, 33]. Using more detailed data of the 2002 SHS, attendance to BC screening was higher in Swiss women than in women from Italy, former Yugoslavia, Portugal and Spain living in Switzerland [34].

In relation to lifestyle factors, represented by smoking habits, alcohol intake, physical activity and attention to diet, only moderate alcohol consumption in the Frenchspeaking region showed an association with $\mathrm{BC}$ screening; however, no statistically significant interactions between the two regions were observed. There is some evidence from other studies that former smokers have a higher attendance to $\mathrm{BC}$ screening $[35,36]$, but many previous studies failed to distinguish between former smokers and those who had never smoked. As Vander Weg [36] pointed out, former smokers may see themselves with a higher cancer risk due to their smoking habits in the past and, therefore, may be more motivated to adhere to screening recommendations than nonsmokers. The findings of lower rates of mammography among current smokers, which have been rather consistently shown in other studies [7, 35, 36], were not confirmed in the present study and in another survey [22].

In our study, alcohol consumption had no effect on the rates of having had $\mathrm{BC}$ screening with the exception of higher $\mathrm{BC}$ screening attendance of women from the French-speaking region who reported drinking moderate amounts of alcohol. Results from other studies [7, 28] indicate a J-shaped association between alcohol consumption and $\mathrm{BC}$ screening use, where both abstainers and heavy drinkers have lower attendance than women drinking modest amounts. The absence of an association between high and low alcohol intake and mammography attendance in our study may be due to information bias and a lower participation rate of heavy drinkers in research studies [7, 37].

In relation to physical activity, our findings are not in line with the results of previous studies, in which nonattendance to $\mathrm{BC}$ screening was associated with lower leisure time physical activity [7]. There are too few studies analyzing the association between nutritional habits and $\mathrm{BC}$ screening attendance to come to a meaningful conclusion $[38,39]$.

Impaired overall health and more frequent contact with medical doctors, respectively, on the other hand, may have implications for BC screening. Studies have shown that factors such as diabetes, cognitive decline, and depression might negatively affect the receipt of cancer screening $[8,22,28]$. The presence of several comorbid conditions might increase the opportunity of receiving cancer screening or diagnosis, however, because of more frequent contact with medical doctors. This could be an explanation for the positive association observed between visits to a physician (compared to none) and higher attendance to $\mathrm{BC}$ screening in the present and other studies [40].

Schumacher et al. [22] observed in their Education and Research Towards Health study that those women who had had other screening tests (cervical and colorectal cancer screening) were much more likely to have received mammography in the past two years. This was true for opportunistic and organized screening, as in the present study. Similar results were seen for organized BC screening in a study carried out in Geneva [41]. Individuals who participate in multiple cancer screenings may be more health-conscious, and/or more knowledgeable about cancer screening tests than those who do not $[9,28,42]$. Those with low attendance to screening tests, on the other hand, may be more critical about the benefits of the screening, including anxiety related to false positive results [43] and inaccurate knowledge and negative mammography beliefs such as that mammography may be harmful, is only needed when symptoms are present, is not necessary, is painful, etc. [42].

\section{Study strengths and limitations}

One strength of our study is the large representative sample of individuals 15 years and older living in Switzerland, allowing for limitation of our analyses to women aged 50-69 years. This study also has several limitations. It is a cross-sectional survey, thus, causality cannot be inferred. In addition, data were self-reported. Women, for example, tend to overestimate their attendance to cancer screening according to the recommendations [44]. This could result in reporting and/or recall biases. Furthermore, $46 \%$ of eligible subjects did not participate in the SHS survey. However, we hypothesize that with respect to mammography attendance rates our survey cohort represents the general population very well because the attendance to the mammography screening programs in the French-speaking cantons were similar to the official data of Swiss Cancer Screening in 2011 (51 \%) [4]. In addition, the use of weighting factors allowed for the extrapolation of the results in relation to age, gender, region and nationality from the sample to the total population living in Switzerland [17]. Furthermore, attendance to opportunistic or organized screening was not clear-cut in the present study, i.e. in the Germanand in the French-speaking regions, $10.1 \%$ and $55.1 \%$, respectively, had a mammography in the context of a screening program, i.e. in the German-speaking region 
$16.8 \%$ attended mammography on their own initiative, $73.1 \%$ followed the advice of a medical doctor (Frenchspeaking region: $8.5 \%$ and $36.5 \%$, respectively). Women with a personal or family history of breast diseases might undergo regular radiologic breast imaging and thus, do not attend a screening $\mathrm{BC}$ program. In particular, women who had mammography in previous years in private radiology practices might prefer to continue these examinations in this trusted setting.

Finally, other factors that may be significant determinants of $\mathrm{BC}$ screening utilization have not been recorded in the current study $[20,21,42,45]$, such as promotion of $\mathrm{BC}$ screening by the government, cancer leagues, medical organizations and lay press. Furthermore, personal or family BC history, knowledge and beliefs in the benefits of screening, and attitude of gynecologists and other medical doctors [46, 47] towards BC screening may be of importance.

\section{Conclusion}

The effect of socio-demographic, lifestyle and health factors and screening behavior other than mammography on non-attendance to $\mathrm{BC}$ screening did not differ between opportunistic and organized screening in Switzerland and did not explain the large differences in $\mathrm{BC}$ screening attendance between the two regions. Physicians' recommendations regarding mammography and/or invitations to attend organized screening should be investigated as potential explanations for the lower attendance rate in the German-speaking region. The negative effect of nonattendance to cervical and colorectal cancer screening on BC screening in both regions may reflect women's negative beliefs and anxiety. This should also be further investigated.

\section{Abbreviations}

BC: Breast cancer; BMI: Body mass index; MHI-5: 5-item mental health index; SFSO: Swiss Federal Statistical Office; SHS: Swiss health survey

\section{Acknowledgment}

The authors thank the Swiss Federal Office of Statistics for permission to use the data of the 2012 Swiss Health Survey.

\section{Funding}

There was no funding for the research reported in the present article.

\section{Availability of data and materials}

Individual data of the Swiss Health Survey are property of the Swiss Federal Statistical Office (SFSO) and may only be made available by SFSO. Requests for access have to be submitted to Mr. Marco D'Angelo (head of division, MarcoDAngelo@bfs.admin.ch).

For information contact sgb12@bfs.admin.ch.

\section{Authors' contributions}

$M E, A R$ and UG designed the study. AR performed the statistical analyses. ME wrote the manuscript. All authors contributed to the interpretation of the data and edited the manuscript. ME and UG supervised the study. All authors contributed to and have approved the final manuscript.

\section{Competing interests}

The authors declare that there are no financial or personal relationships with other people or organizations that could inappropriately influence the work reported or the conclusions, implications, or opinions stated.

\section{Consent for publication}

Not applicable.

\section{Ethics approval and consent to participate}

Data collection and data storage for the Swiss Health Survey (Schweizerische Gesundheitsbefragung) does not require formal approval by an ethical committee. This data collection is specifically permitted under Swiss law (Verordnung über die Durchführung von statistischen Erhebungen des Bundes vom 30. Juni 1993 (SR 431.012.1) and Verordnung über die eidgenössische Volkszählung vom 19. Dezember 2008 (SR 431.112.1). Individuals invited to participate received a brief description of the study and could decline to participate or withdraw at any time. Participants' responses were treated confidentially and aggregated anonymous responses were utilized for analyses presented herein.

\section{Author details}

1Division of Chronic Disease Epidemiology, Epidemiology, Biostatistics and Prevention Institute, University of Zurich, Hirschengraben 84, CH-8001 Zurich, Switzerland. ${ }^{2}$ Department of Gynecology \& Obstetrics, Spital Grabs, Spitalstrasse 44, CH-9472 Grabs, Switzerland. ${ }^{3}$ Breast Center St. Gallen, Rorschacher Strasse 150, CH-9006 St.Gallen, Switzerland. ${ }^{4}$ Department of Gynecology and Obstetrics, Kantonsspital Baden AG, Interdisciplinary Breast Centre, CH-5404 Baden, Switzerland. ${ }^{5}$ Department of Gynecology and Obstetrics, University Hospital Basel (UHB), Spitalstrasse 21, CH-4031 Basel, Switzerland. ${ }^{6}$ Breast Center Zurich, Seefeldstrasse 214, CH-8008 Zurich, Switzerland.

Received: 14 July 2015 Accepted: 15 September 2016

Published online: 23 September 2016

References

1. Perry N, Broeders M, de Wolf C, Tornberg S, Holland R, von Karsa L. European guidelines for quality assurance in breast cancer screening and diagnosis. Fourth edition—summary document. Ann Oncol. 2008;19(4):614-22.

2. Ouedraogo S, Dabakuyo-Yonli TS, Amiel P, Dancourt V, Dumas A, Arveux P. Breast cancer screening programmes: challenging the coexistence with opportunistic mammography. Patient Educ Couns. 2014;97(3):410-7.

3. Bulliard JL, Ducros C, Dayer E, Arzel B, Levi F. Variation in performance in low-volume mammography screening programmes: experience from Switzerland. Cancer Epidemiol. 2011;35(3):293-7.

4. Swiss cancer screening. Available: http://www.brust-screening.ch. Accessed 18 Sept 2016.

5. Bryan L, Westmaas $L$, Alcaraz K, Jemal A. Cigarette smoking and cancer screening underutilization by state: BRFSS 2010. Nicotine Tob Res. 2014; 16(9):1183-9.

6. Martin-Lopez R, Hernandez-Barrera V, De Andres AL, Garrido PC, De Miguel AG, Garcia RJ. Breast and cervical cancer screening in Spain and predictors of adherence. Eur J Cancer Prev. 2010;19(3):239-45.

7. Lagerlund M, Drake I, Wirfalt E, Sontrop JM, Zackrisson S. Health-related lifestyle factors and mammography screening attendance in a Swedish cohort study. Eur J Cancer Prev. 2015;24(1):44-50.

8. Xiang X. Serious psychological distress as a barrier to cancer screening among women. Womens Health Issues. 2015;25(1):49-55.

9. Gonzalez P, Castaneda SF, Mills PJ, Talavera GA, Elder JP, Gallo LC. Determinants of breast, cervical and colorectal cancer screening adherence in Mexican-American women. J Community Health. 2012;37(2):421-33.

10. Damiani G, Federico B, Basso D, Ronconi A, Bianchi CB, Anzellotti GM, Nasi G, Sassi F, Ricciardi W. Socioeconomic disparities in the uptake of breast and cervical cancer screening in Italy: a cross sectional study. BMC Public Health. 2012;12:99.

11. Martin-Lopez R, Jimenez-Garcia R, Lopez-de-Andres A, Hernandez-Barrera V, Jimenez-Trujillo I, Gil-de-Miguel A, Carrasco-Garrido P. Inequalities in uptake of breast cancer screening in Spain: analysis of a cross-sectional national survey. Public Health. 2013;127(9):822-7. 
12. Duport N. Characteristics of women using organized or opportunistic breast cancer screening in France. Analysis of the 2006 French Health, Health Care and Insurance Survey. Rev Epidemiol Sante Publique. 2012;60(6):421-30.

13. Andreeva VA, Pokhrel P. Breast cancer screening utilization among Eastern European immigrant women worldwide: a systematic literature review and a focus on psychosocial barriers. Psychooncology. 2013;22(12):2664-75.

14. Walsh B, Silles $M, O^{\prime}$ Neill C. The importance of socio-economic variables in cancer screening participation: a comparison between population-based and opportunistic screening in the EU-15. Health Policy. 2011;101(3):269-76.

15. Palencia L, Espelt A, Rodriguez-Sanz M, Puigpinos R, Pons-Vigues M, Pasarin MI, Spadea T, Kunst AE, Borrell C. Socio-economic inequalities in breast and cervical cancer screening practices in Europe: influence of the type of screening program. Int J Epidemiol. 2010;39(3):757-65.

16. Eichholzer M, Richard A, Rohrmann S, Schmid S, Guth U. Overweight, obesity, and breast cancer screening: results from the 2012 Swiss Health Survey. Eur J Cancer Prev. 2016;25(2):130-36

17. Swiss Federal Office of Statistics. Schweizerische Gesundheitsbefragung 2012. Available: www.sgb12.bfs.admin.ch/. Accessed 18 Sept 2016.

18. WHO. Mental Health action plan 2013-2010. WHO 2013. 2013.

19. Bundesamt für Sport BASPO BfGB, Gesundheitsförderung, Schweiz bBfU, Suva, Netzwerk, Schweiz. GuB. Gesundheitswirksame Bewegung. Magglingen: BASPO; 2013.

20. Carrasco-Garrido P, Hernandez-Barrera V, de Lopez Andres A, Jimenez-Trujillo I, Gallardo Pino C, Jimenez-Garcia R. Awareness and uptake of colorectal, breast, cervical and prostate cancer screening tests in Spain. Eur J Pub Health. 2014; 24(2):264-70.

21. Bonfill X, Marzo M, Pladevall M, Marti J, Emparanza Jl. Strategies for increasing women participation in community breast cancer screening. Cochrane Database Syst Rev. 2001;1:CD002943.

22. Schumacher MC, Slattery ML, Lanier AP, Ma KN, Edwards S, Ferucci ED Tom-Orme L. Prevalence and predictors of cancer screening among American Indian and Alaska native people: the EARTH study. Cancer Causes Control. 2008;19(7):725-37.

23. Cabeza E, Esteva M, Pujol A, Thomas V, Sanchez-Contador C. Social disparities in breast and cervical cancer preventive practices. Eur J Cancer Prev. 2007;16(4):372-9.

24. Luengo-Matos S, Polo-Santos M, Saz-Parkinson Z. Mammography use and factors associated with its use after the introduction of breast cancer screening programmes in Spain. Eur J Cancer Prev. 2006;15(3):242-8.

25. von Euler-Chelpin M, Olsen AH, Njor S, Vejborg I, Schwartz W, Lynge E. Socio-demographic determinants of participation in mammography screening. Int J Cancer. 2008;122(2):418-23.

26. Swiss Federal Office of Public Health. FAQ about the requirement to take out insurance. Available: http://www.bag.admin.ch/themen/krankenversicherung/ 04114/04123/index.html?lang=en. Accessed 18 Sept 2016.

27. Duport N, Ancelle-Park R. Do socio-demographic factors influence mammography use of French women? Analysis of a French cross-sectional survey. Eur J Cancer Prev. 2006;15(3):219-24.

28. Sicsic J, Franc C. Obstacles to the uptake of breast, cervical, and colorectal cancer screenings: what remains to be achieved by French national programmes? BMC Health Serv Res. 2014;14:465.

29. Bulliard JL, de Landtsheer JP, Levi F. Profile of women not attending in the Swiss Mammography Screening Pilot Programme. Breast. 2004;13(4):284-9.

30. Chamot E, Perneger TV. Men's and women's knowledge and perceptions of breast cancer and mammography screening. Prev Med. 2002;34(3):380-5.

31. Lynge E, Olsen AH, Fracheboud J, Patnick J. Reporting of performance indicators of mammography screening in Europe. Eur J Cancer Prev. 2003; 12(3):213-22.

32. Wang $H$, Karesen $R$, Hervik A, Thoresen SO. Mammography screening in Norway: results from the first screening round in four counties and cost-effectiveness of a modeled nationwide screening. Cancer Causes Control. 2001;12(1):39-45.

33. Jack RH, Moller $H$, Robson T, Davies EA. Breast cancer screening uptake among women from different ethnic groups in London: a population-based cohort study. BMJ Open. 2014;4(10), e005586.

34. Fontana M, Bischoff $A$. Uptake of breast cancer screening measures among immigrant and Swiss women in Switzerland. Swiss Med Wkly. 2008;138(49-50):752-8.

35. Caleffi M, Ribeiro RA, Bedin Jr AJ, Viegas-Butzke JM, Baldisserotto FD, Skonieski GP, Giacomazzi J, Camey SA, Ashton-Prolla P. Adherence to a breast cancer screening program and its predictors in underserved women in southern Brazil. Cancer Epidemiol Biomarkers Prev. 2010;19(10):2673-9.

36. Vander Weg MW, Howren MB, Cai X. Use of routine clinical preventive services among daily smokers, non-daily smokers, former smokers, and never-smokers. Nicotine Tob Res. 2012;14(2):123-30.

37. Feunekes Gl, van't Veer P, van Staveren WA, Kok FJ. Alcohol intake assessment: the sober facts. Am J Epidemiol. 1999;150(1):105-12.

38. Gorin SS, Jacobson J. Diet and breast cancer surveillance behaviors among Harlem women. Ann N Y Acad Sci. 2001;952:153-60.

39. Galan I, Rodriguez-Artalejo F, Diez-Ganan L, Tobias A, Zorrilla B, Gandarillas A. Clustering of behavioural risk factors and compliance with clinical preventive recommendations in Spain. Prev Med. 2006;42(5):343-7.

40. Lopez-de-Andres A, Martin-Lopez R, Hernandez-Barrera V, Carrasco-Garrido P, Gil-de-Miguel A, MM E y P, Jimenez-Garcia R. Predictors of breast and cervical cancer screening in a Spanish metropolitan area. J Women's Health. 2010;19(9):1675-81.

41. Cullati S, Charvet-Berard Al, Perneger TV. Cancer screening in a middle-aged general population: factors associated with practices and attitudes. BMC Public Health. 2009;9:118.

42. Schueler KM, Chu PW, Smith-Bindman R. Factors associated with mammography utilization: a systematic quantitative review of the literature. J Womens Health (Larchmt). 2008;17(9):1477-98.

43. Meystre-Agustoni G, Paccaud F, Jeannin A, Dubois-Arber F. Anxiety in a cohort of Swiss women participating in a mammographic screening programme. J Med Screen. 2001;8(4):213-9.

44. Howard M, Agarwal G, Lytwyn A. Accuracy of self-reports of Pap and mammography screening compared to medical record: a meta-analysis. Cancer Causes Control. 2009;20(1):1-13.

45. Achat $\mathrm{H}$, Close $\mathrm{G}$, Taylor R. Who has regular mammograms? Effects of knowledge, beliefs, socioeconomic status, and health-related factors. Prev Med. 2005:41(1):312-20.

46. Bulliard JL, de Landtsheer JP, Levi F. Participation in Swiss mammography screening programmes: key role of physicians. Praxis. 2005;94(36):1381-7.

47. Keller B, Stutz EZ, Tibblin M, Ackermann-Liebrich U, Faisst K, Probst-Hensch N. Screening mammographies in Switzerland: what makes female and male physicians prescribe them? Swiss Med Wkly. 2001;131(21-22):311-9.

\section{Submit your next manuscript to BioMed Central and we will help you at every step:}

- We accept pre-submission inquiries

- Our selector tool helps you to find the most relevant journal

- We provide round the clock customer support

- Convenient online submission

- Thorough peer review

- Inclusion in PubMed and all major indexing services

- Maximum visibility for your research

Submit your manuscript at www.biomedcentral.com/submit 